\title{
Comparison of Fully Pneumatic and Pneumatic - Electric Hybrid Configurations for Propulsion of A Refrigerated Vehicle
}

\author{
Midhun V.S ${ }^{1}$, A Ramesh ${ }^{2}$ and Sathyanandan $\mathrm{M}^{1}$ \\ ${ }^{1}$ M/S Nissan Ashokleyland Technologies Limited, No 19, Venkatanarayanan Road, \\ T Nagar, Chennai, India (Corresponding author:midhunvs@ymail.com) \\ ${ }^{2}$ I C Engines Laboratory, Mechanical Engineering Department, IIT Madras, \\ Chennai, India
}

Received: January 27, 2014; Accepted: February 27, 2014

Publication: June 3, 2014

\begin{abstract}
Two different configurations of using a multistage air powered engine with variable valve timing for powering a light transport vehicle were evaluated through thermodynamic simulation. The expanded cold air between the stages was used to refrigerate the cold space and thereby get reheated. However this cannot meet the refrigeration load completely. Thus in the first configuration the air engine provided the shaft power for propulsion and for additional refrigeration. In the second configuration the air engine was connected in parallel to a motor/generator and Li-ion battery. The total refrigeration load was met by the expanded cold air between stages. The additional shaft power available was used to charge the battery. After depletion of the compressed air, the battery was used to provide shaft power and refrigeration. The range of the hybrid configuration was evaluated to be slightly higher.
\end{abstract}

Keywords: Multistage expansion, variable valve timing, refrigeration, hybrid layout.

Journal of Green Engineering, Vol. 1, 49-70.

doi: 10.13052/jge1904-4720.414

(c) 2014 River Publishers. All rights reserved. 


\section{Introduction}

The growing worldwide concern on environmental and energy related issues caused by transportation has brought about an increased demand for cleaner and more energy efficient vehicles. Till date control of emissions from conventional internal combustion engines has been mainly by the use of alternate fuels like liquefied petroleum gas (LPG), compressed natural gas (CNG), alcohols and bio diesel. However, many of these fuels also tend to increase the net $\mathrm{CO}_{2}$ levels in the atmosphere. $\mathrm{CO}_{2}$ neutral fuels are hydrogen and others produced from completely renewable sources. Hydrogen can be used in IC engines and in fuel cells. However, these technologies have still not been implemented on a large scale due to several practical challenges. Hence, researchers all over the globe are on the lookout for alternative propulsion systems. In this context, compressed air powered propulsion systems have many attractive features in comparison to some of the alternatives that are being evaluated.

Compressed air vehicles have been in existence since late $19^{\text {th }}$ century, but the advent of fossil fuels with the advantage of higher energy density had diminished the interest in this technology. One of the earliest theoretical studies on compressed air based prime movers was a thermodynamic analysis done by Havemann and Rao [1] who simulated a hot air engine with multistage expansion and also studied the effect of pulsations on heat exchanger effectiveness when used in this application. A collection of the methodologies for using compressed air for propulsion of vehicles has been done by Scott Robertson [2]. From the compilation it is seen that compressed air propulsion has been generally achieved in several ways - dedicated air powered engine, compressed air with hydrocarbon fuels and compressed air with electric power in the hybrid mode. A simple thermodynamic simulation of multistage expansion and compression was done by Bossel [3]. He simulated the effect of increased number of stages of expansion and compression, and found that there is about $50 \%$ improvement from single stage to 4 stage expansion. Hence, good efficiency is possible from the air engine. Carvalho [4] conducted a theoretical available energy analysis for the air powered engine and determined its relation with storage pressure. The study compared the energy density of compressed air with hydrocarbons and found that the former is two orders of magnitude lower than conventional fuels, but comparable to Ni based batteries. The advantages of compressed air storage over batteries are: no environmental

hazards of disposal, lower cost and longer life. However, the efficiency of compressed air devices needs to be improved for wide spread application. 
Creutzig et al. [5] made an analysis of the thermodynamic efficiency of air powered engines and compared it with the chemical storage potential in batteries. It was concluded that compressed air alone is not comparable to electric vehicles as regards well to wheel efficiency and greenhouse gas emissions, but pneumatic - combustion hybrid is a feasible and efficient solution.

Analysis of thermodynamic cycles for automotive engines was done by Schechter [6] to capture the braking regeneration using compressed air and reuse this stored energy during acceleration. Here compressed air obtained during braking is stored in tanks and then fed into the engine during acceleration. This reduces turbo lag. An actual pneumatic hybrid engine model was made by Trajkovic et al. [7] who modified an existing single cylinder diesel engine by introducing an electro mechanical valve to control the air moving to and from a compressed air tank. The engine used air compression for regenerative braking along with the air tank.

In the present work a light transport vehicle (LTV) which also needs refrigeration has been considered. A multistage air powered based system capable of producing shaft power and refrigeration simultaneously is the prime mover. Two power train versions; one which uses only an air powered engine and the other which is a hybrid version which uses an air powered engine along with an electrical drive have been simulated and compared to evaluate their range capabilities.

\section{Theory of Fully Pneumatic and Pneumatic Hybrid Configuration Considered in this Work}

A LTV with a gross mass of $2500 \mathrm{~kg}$ has been considered for the simulations. Based on the resistances to motion, the power needed to drive the vehicle at different speeds was calculated using standard expressions and co-efficient as per Automotive Handbook from Bosch [8]. The most representative speed for the simulation was taken based on the driving cycle that is used in India for emission certification namely the modified Indian driving cycle as per Indian CMVR regulations [9]. In this cycle, most of the driving occurs at $50 \mathrm{kmph}$. Hence, all the present calculations were based on the assumption that the vehicle is driven at a constant speed of $50 \mathrm{kmph}$. The power needed to propel this vehicle is $7.06 \mathrm{~kW}$ at this speed. The vehicle is also assumed to be refrigerated. On examination of similar vehicles it was found that the refrigeration requirement is about $9 \mathrm{~kW}$ [10] as per a typical refrigeration compressor specification. The LTVs which are used to carry perishable goods 


\section{Midhun V.S et al.}

typically require the refrigerated space to be maintained at $-5^{\circ} \mathrm{C}$ as per Dossat [11]. Hence, for the purposes of calculations the above values were used. The two different power train versions that were simulated are described below.

The first configuration, namely the fully pneumatic version shown in Figure 1 uses only an air powered engine for shaft power generation and refrigeration. The shaft power of $7.06 \mathrm{~kW}$ is produced by the engine. The cold air between the stages is passed through heat exchangers which use the hot air $\left(-5^{\circ} \mathrm{C}\right)$ from the refrigerated space for reheating. Thus in this case the refrigeration effect is obtained while reheating the cold air between the expander stages and also from the cold air that exits the last stage. This does not amount to the total refrigeration requirement of $9 \mathrm{~kW}$. Additional refrigeration to meet the total need is met by also running a refrigeration compressor by the air engine (expander). Referring simulation by Creutzig et al., [5] the compressed air is stored in a composite cylinder at 300 bar and ambient temperature ( $298 \mathrm{~K})$. Three stage expansion has been assumed based on calculations discussed later. The pressure of compressed air falls as the vehicle is driven. Hence, the valve timing is continuously varied so that the compressed air exits at atmospheric pressure always i.e. after complete expansion. The system is stopped when the open period of the inlet valve of the first stage becomes $180^{\circ}$ i.e. from TDC to BDC. At this stage the first stage becomes redundant. (The corresponding pressure in the compressed air tank is called the least operable pressure). The work output of the engine per cycle

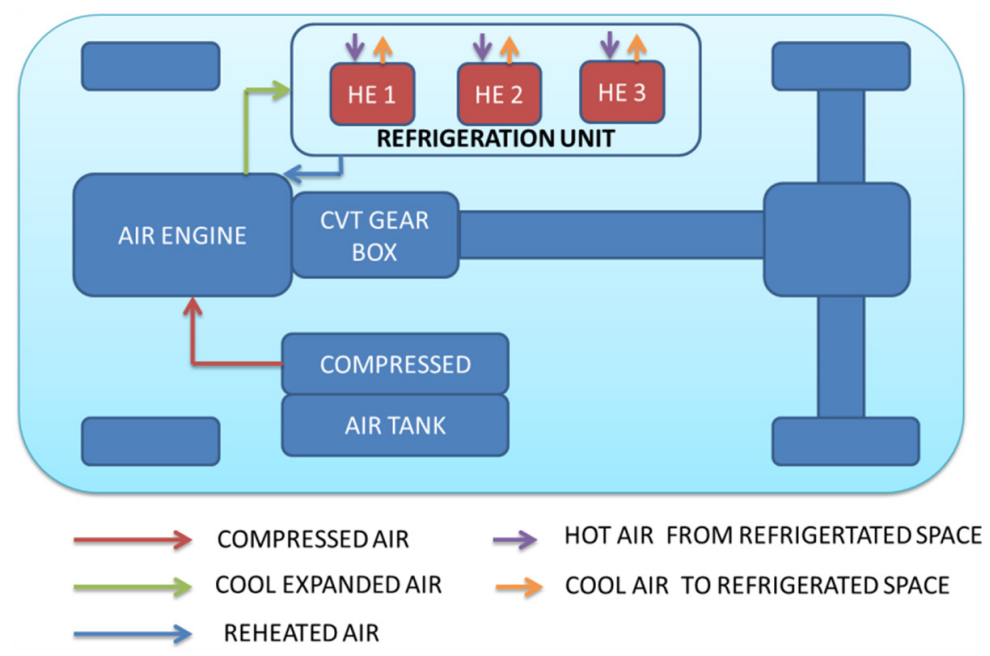

Figure 1 Fully pneumatic vehicle (Configuration 1) 
decreases as the air pressure falls. Thus the engine has to be run at increasing speeds (for obtaining a constant power output) as the pressure in the tank drops to compensate for the reduction in the energy density of air. Hence, a continuously variable transmission is assumed to be used between the air engine and the wheels. The air in the compressed air tank is assumed to be at a constant temperature of $298 \mathrm{~K}$ (atmospheric temperature).

The second power train configuration shown in Figure 2 is a hybrid using an additional Li-ion battery and motor generator. The power outputs of the motor generator and air powered engine are coupled through the gear box shown. In this case the battery and the compressed air tank are fully charged at the beginning of the cycle. First the energy in the battery is used to produce shaft power and refrigeration till it is fully discharged. Then the air powered engine is started. The air engine is run so that reheating between the stages and cold air that is finally let out produce the required refrigeration effect of $9 \mathrm{~kW}$ always. If a refrigeration effect of $9 \mathrm{~kW}$ is to be generated by the engine then the shaft power will exceed the requirement of $7.06 \mathrm{~kW}$. In this case the extra power is used to charge the Li-ion battery through the motor generator. Here again the air powered engine is stopped when the open period of the inlet valve of the first stage becomes $180^{\circ}$ i.e. from TDC to BDC. As mentioned earlier, at this condition the first stage of the engine becomes

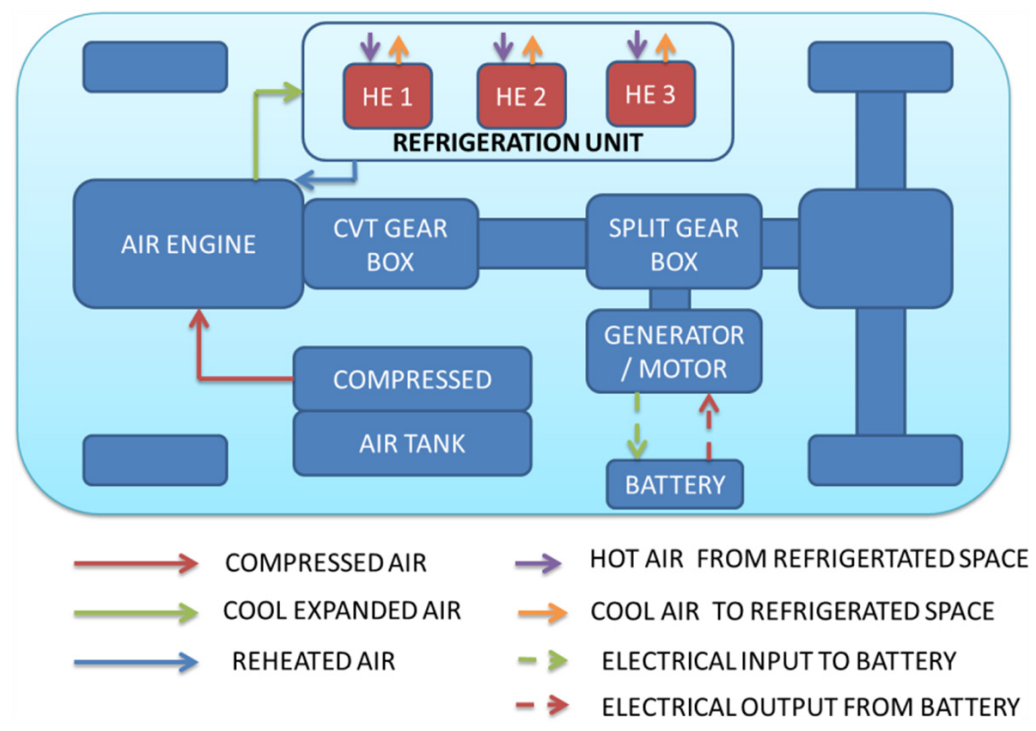

Figure 2 Pneumatic battery hybrid vehicle (Configuration 2) 
redundant. There after the energy in the battery is used to drive the vehicle and also produce the needed refrigeration through a refrigeration compressor. The size of the battery will depend on the amount of excess work from the air engine to be stored. This will affect the amount of electrical energy available initially.

\section{Details of Air Powered Engine (APE) and Refrigeration System}

APE is a multistage expansion reciprocating engine, with reheating. The valve timing is assumed to be controlled electromechanically. Hence, variable valve timing is possible. The air engine has three stages of expansion as seen in Figures 1 and 2. Air enters the first stage of expansion at the tank pressure and the pressure in between stages is defined by the timing of the inlet valve timing and the expansion ratio i.e. ratio of volume at BDC to volume at TDC. The temperature of air also drops well below atmospheric condition during expansion. Flow losses are assumed to be zero. The expansion process is assumed to be isentropic. Even during the air intake process no heat transfer is assumed.

During each stage of expansion the pressure drops and with it the air temperature drops well below atmospheric temperature. The air is reheated by passing it into the refrigeration unit which is assumed to be maintained at $-5^{\circ} \mathrm{C}$ for storing perishable goods. The air in the refrigeration space is at higher temperature than the cold expanded air hence the heat exchanger reheats the latter. The reheated air enters the subsequent stage of expansion. The same function is done on all heat exchangers (HE1, HE2, HE3). An effectiveness of 0.9 is assumed for the heat exchangers as per Doty [12]. The total output from the engine is the summation of the shaft work and refrigeration work, considering a COP of 1.55[10].

In Figure 3, an example of the p-v curve of a 3 stage APE shows that air enters the engine at 125 bar in the $1^{\text {st }}$ stage and exits at 1 bar in the $3^{\text {rd }}$ stage. The significant points of operation in each stage are 1(IVO), 2(IVC), $3(\mathrm{EVO}), 4(\mathrm{EVC})$. Each stage has 4 processes, process 1 to 2 is induction (constant pressure), 2 to 3 is isentropic expansion, 3 to 4 is exhaust (constant pressure) and 4 to 1 is isentropic compression. In the APE, the inlet valve opening is fixed at TDC (point 1) and exhaust valve opening is fixed at $\mathrm{BDC}$ (point 3). It is assumed that a variable valve timing system is used to control the closing time of the inlet (point 2) and exhaust valves (point 4). The 

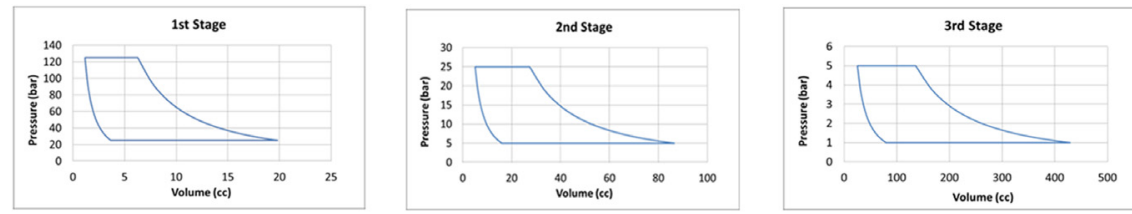

Figure 3 P V Diagram of 3 stage expansion with reheating

timings are based on the mass of air required to generate required work output from cycle.

The shaft work from the air engine is transmitted to the wheels through a continuously variable transmission (CVT) gear box. The engine extracts maximum work from the compressed air by expanding to atmospheric pressure, even when the inlet air pressure varies. This is because of the variable valve timing system.

\section{Method of Determination - Number of Stages and Size of the Ape}

As the number of stages in the APE increases, the efficiency also goes up since it will be possible to reheat the air between the stages. In the limit, i.e. infinite number of stages, this will tend to isothermal expansion at atmospheric temperature. However, from a practical point of view only a few stages can be used. Hence the first phase of the simulation was to determine the number of stages of the APE that could be practically used. For this a parameter called isothermal efficiency $\eta_{\text {eff }}$ was used and is obtained using the equations given below.

$$
\begin{gathered}
W_{n-\text { stage }}=\left(N^{*} R^{*} T_{\text {in }}^{*} n /(n-1)\right)^{*}\left(1-\left(P_{\text {atm }} / P_{\text {in }}\right)\left((n-1) /\left(N^{*} n\right)\right)\right) \\
W_{\text {isothermal }}=R^{*} T_{\text {in }}^{*} \ln \left(P_{\text {in }} / P_{\text {atm }}\right) \\
\eta_{\text {eff }}=\left(W_{n \text {-stage }} / W_{\text {isothermal }}\right)^{*} 100
\end{gathered}
$$

Figure 4 indicates the effect of number of stages on the isothermal efficiency. It is seen that the benefits are not significant beyond three stages. Thus for the simulation the number of stages was taken as 3 since the 3 stage expansion is a good compromise between efficiency and complexity - 3 stage 


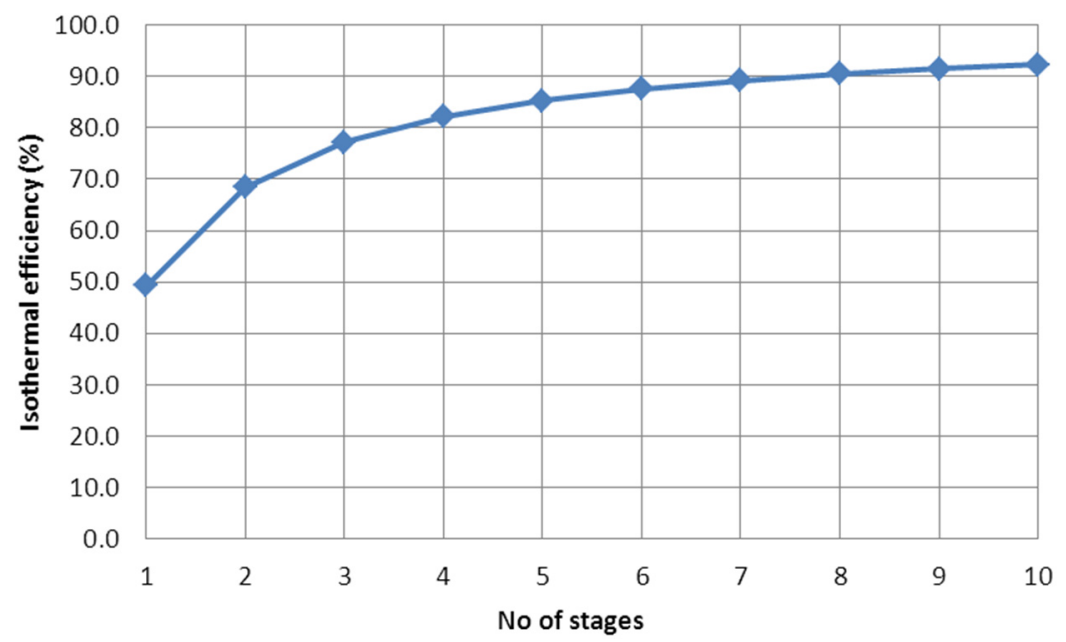

Figure 4 Effect of number of stages

is $11 \%$ more efficient more efficient than 2 stage only $6 \%$ less efficient than 4 stage.

Once the number of stages was fixed the dimensions of the engine was determined based on the maximum work that can be extracted from a given volume of air with certain conditions. The power needed was taken as $7.06 \mathrm{~kW}$ at a speed of $1875 \mathrm{rpm}$. These values were taken from the power requirement of a conventional LTV at a speed of $50 \mathrm{kmph}$ and corresponding engine speed. The dimensions (displacement volume of the engine) for different constant supply pressures (System Design Pressure) ranging from 300 to 15 bar were obtained with the given power and speed requirements and for three stages. Subsequently the total work developed by each of these engines was evaluated by simulation. This was done for a fixed volume of the compressed air tank and an initial pressure of 300 bar. In this case the pressure in the tank falls as time progresses and the cumulative work output till the minimum tank pressure (lowest operable pressure) is reached was calculated for each engine size. The lowest operable pressure occurs when intake valve closing (point 2 in Figure 3) in the first stage of expansion occurs BDC (point 3 in Figure 3), making the first stage redundant due to no expansion work in that stage. The engine size that provided the maximum cumulative work output is taken up for further simulation. Figure 5 indicates that the maximum cumulative work occurs when the engine is designed for a supply pressure of 25 bar (even when 


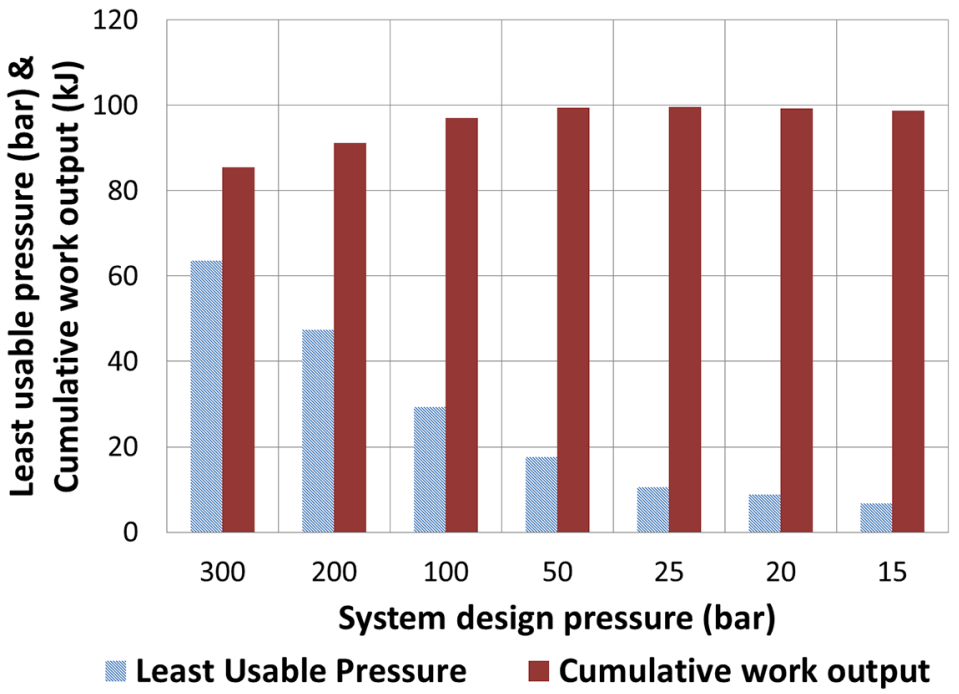

Figure 5 Best engine size selection

Table 1 Engine size for 25 bar constant input pressure

\begin{tabular}{lccc}
\hline $\begin{array}{l}\text { Stages of } \\
\text { expansion }\end{array}$ & $\begin{array}{l}\text { Volume at TDC } \\
(\mathrm{cc})\end{array}$ & $\begin{array}{l}\text { Volume at BDC } \\
(\mathrm{cc})\end{array}$ & $\begin{array}{l}\text { Displacement volume } \\
(\mathrm{cc})\end{array}$ \\
\hline 1 & 2.64 & 45.04 & 42.4 \\
2 & 8.57 & 145.79 & 137.22 \\
3 & 31.29 & 532 & 500.71 \\
\hline
\end{tabular}

the operating pressure varies between 300 bar and the lowest operable pressure). Hence, the dimensions of the engine corresponding to this design were taken as inputs in subsequent simulations. The dimensions are given in Table 1.

\section{Simulation of Fully Pneumatic and Pneumatic Battery Hybrid Configurations}

The dimensions of the engine were taken from Table 1. A program was written in Matlab for simulating the different processes in the APE and in the heat exchangers. The following are the assumptions that were made:

- Ambient (outlet) air pressure $\left(\mathrm{P}_{a t m}\right)=1$ bar

- Ratio of specific heats for of air $(n)=1.4$

- Supply air temperature / Ambient temperature $\left(\mathrm{T}_{a t m}\right)=298.15 \mathrm{~K}$

- Gas constant of air $(\mathrm{R})=287 \mathrm{~J} / \mathrm{kg} \mathrm{K}$ 
- Pressure loss heat exchanger stages $=0$

- Effectiveness of the heat exchanger $=\varepsilon=0.9$

- Temperature of air in refrigerated space $=\mathrm{T}_{\text {refri }}=-5^{\circ} \mathrm{C}$

- Specific heat capacity of air $=\mathrm{C}_{a i r}=1013 \mathrm{~J} / \mathrm{kg} \mathrm{K}$

The work of each stage of the APE was calculated based on equation (4) assuming isentropic expansion without pressure loss. The total work was obtained from equation (5). Heat transfer from the air in the cold space to the cold air between the stages and after the last stage was calculated using equation (6). The total refrigeration produced is given by equation (7). The equations are based on thermodynamic relations by Nag [13] and Incropera [14].

$$
\begin{gathered}
W_{\text {stage }}=P_{1}^{*}\left(v_{2}-v_{1}\right)+\left(\left(\left(P_{2}^{*} v_{2}\right)-\left(P_{3}^{*} v_{3}\right)\right) /(n-1)\right)-\left(P_{3}^{*}\left(v_{3}-v_{4}\right)\right) \\
-\left(\left(P_{1}^{*} v_{1}\right)-\left(P_{4}^{*} v_{4}\right)\right) /(n-1) \\
W_{\text {shaft }}=\sum W_{\text {stage }} \\
H_{\text {trans }}=\left(\varepsilon^{*} C_{\text {rate }}^{*}\left(T_{\text {refri }}-T_{\text {exp }}\right)\right) \\
H_{\text {refri }}=\sum H_{\text {trans }}
\end{gathered}
$$

\subsection{Configuration 1- Fully Pneumatic Operation}

In the first stage (fully pneumatic operation) of the simulation the APE was run in such a way that it caters to the shaft power requirements of the LTV ( $7.06 \mathrm{~kW}$ i.e. $P_{1}$ ) and also simultaneously achieves the needed refrigeration of $9 \mathrm{~kW}$. In this case, since the refrigeration effect produced by all the heat exchangers (Figure 1) did not come up to $9 \mathrm{KW}\left(P_{2}\right)$ and additional shaft power was derived from the APE to run a refrigeration compressor as explained earlier. A COP of 1.55 was assumed for this system. The APE was run at different speeds to meet the power and refrigeration requirements, since the work output per cycle drops as the pressure in the storage cylinder reduces with time. The relevant equations are given below.

$$
P_{\text {shaft }}=W_{\text {shaft }}^{*} N_{\text {rpm }} / 60000
$$




$$
\begin{gathered}
P_{\text {refri }}=H_{\text {refri }}^{*} N_{\text {rpm }} / 60000 \\
\left(P_{\text {shaft }}-P_{1}\right)^{*} C O P+P_{\text {refri }}=P_{2}
\end{gathered}
$$

Based on the above, the speed of the engine $\left(N_{r p m}\right)$ was calculated. This then gave the mass flow rate of air for producing the needed outputs at any given tank pressure. Thus the total time taken till the pressure of the air in the tank dropped to the least operable pressure (discussed earlier) was calculated. The continuously variable transmission ensures that the vehicle speed is maintained at the required $50 \mathrm{kmph}$. Based on these, the total volume of compressed air at 300 bar for a vehicle range of $150 \mathrm{~km}$ was computed. The weight of the energy carrier i.e compressed air tank is then calculated by assuming in to be a composite cylinder referring to the study by Baldwin [15].

\subsection{Configuration 2 - Pneumatic Battery Hybrid Operation}

The pneumatic hybrid version uses both $\mathrm{Li}$ - ion batteries and compressed air as energy carriers. The batteries are assumed to be fully charged initially from an external power supply. The vehicle is then run in the electric mode till the battery is completely drained. Then the APE is run to cater to the required refrigeration ( $9 \mathrm{~kW}$ through the heat exchangers alone) load by adjusting its speed. In this case it is observed that the corresponding shaft power is greater than $7.06 \mathrm{~kW}$ which is the requirement of the LTV. The additional shaft work is stored in the on board Li-ion batteries. The size of batteries required is calculated based on the maximum energy required to be stored. Finally, the APE is stopped when the least operable pressure is reached. At this condition the fully charged batteries provide power to run the vehicle with refrigeration, till they drain out again. The cumulative time taken for the vehicle to consume the full battery charge twice and the full compressed air tank once was calculated. The battery was sized initially using the equations given to store the excess energy from air engine for a volume of 1 liter of compressed air. Hence, the size of the battery could be estimated for any initial volume of compressed air. The total mass of the compressed air tank, air and the corresponding Li-ion battery is iterated till the weight of total energy carrier is same as that in the fully pneumatic version (the previous case). For this combination of compressed air and battery the range that can 
be achieved by the hybrid version was calculated. The following details and equations as per Larminie and Lowry [16] are used:

- Specific energy of $\mathrm{Li}-$ ion $-90 \mathrm{~W} \mathrm{~h} / \mathrm{kg}$

- Energy density of Li - ion - $153 \mathrm{~W} \mathrm{~h} / 1$

- Electric loss considered (charging and discharging efficiency - $95 \%$ )

- No mechanical losses

$$
\begin{gathered}
m_{\text {batt }}=W_{\text {total }}^{*} T_{\text {time }} / B_{\text {sp_en }} \\
V_{\text {batt }}=W_{\text {total }}^{*} T_{\text {time }} / B_{\text {en_den }}
\end{gathered}
$$

\section{Results and Discussion}

\subsection{Full Pneumatic Operation}

The APE is assumed to produce the $7.06 \mathrm{~kW}$ to propel the vehicle and additional shaft power for a refrigeration of $9 \mathrm{~kW}$. It may be noted that the refrigeration in this case is done partly by the heat exchangers (Figure 1) and partly by an additional refrigeration compressor run by the APE. The engine speed needed to produce the shaft power required was computed at varying cylinder pressures. Figure 6 , shows the variation of the work output per cycle, pressure of the compressed air tank and total mass of air consumed by the engine with increasing number of engine cycles (with time). Here the volume of the supply tank has been taken as 1 liter. The total mass of air consumed by the engine changes linearly with number of cycles which indicates that the mass of air consumed per cycle is nearly constant. Since the temperature of air is assumed to be constant in the tank, the pressure falls linearly with mass flow i.e with number of cycles. The work output per cycle falls rapidly as the pressure in the tank reduces to values below 50 bar. This is because the available energy of the air in the tank falls drastically with pressure. The refrigeration effect produced by the reheating is shown in Figure 7. It drops drastically with pressure even though the mass of air per cycle remains constant. This is because the heat transfer in the first stage (which has maximum drop in temperature) drops with decrease in tank pressure. It may be noted in Figure 7 that the temperature drop in the first stage due to expansion becomes insignificant as the number of cycles increases. This is because the intake valve of the first stage closes later towards BDC as the pressure of air in the compressed air tank falls. The lowest usable pressure is about 10 bar when the work output from 1st stage tends to zero. This is the least operable pressure and here the APE is stopped. The time taken for 


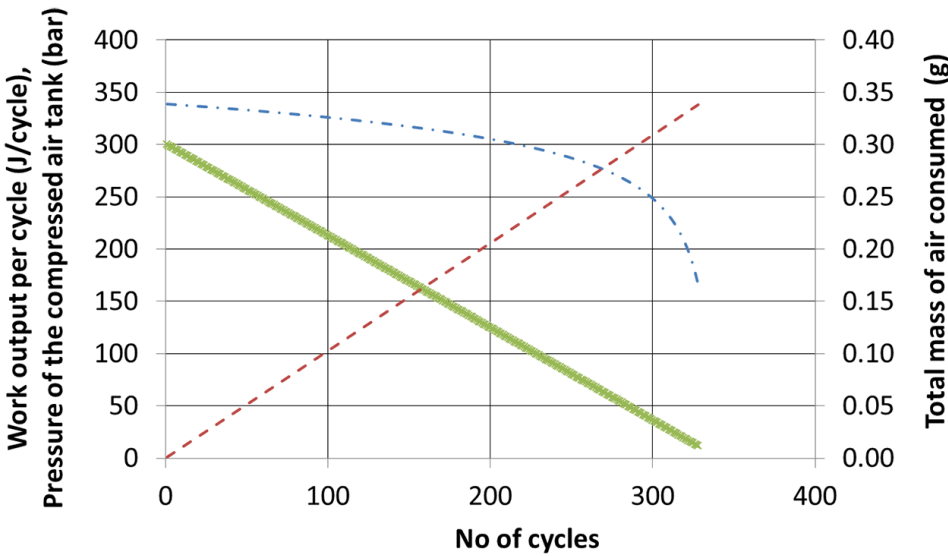

- - -Shaft Work per cycle $\quad-$ Pressure of compressed air tank

- - Total mass of air consumed

Figure 6 Air engine operation characteristics

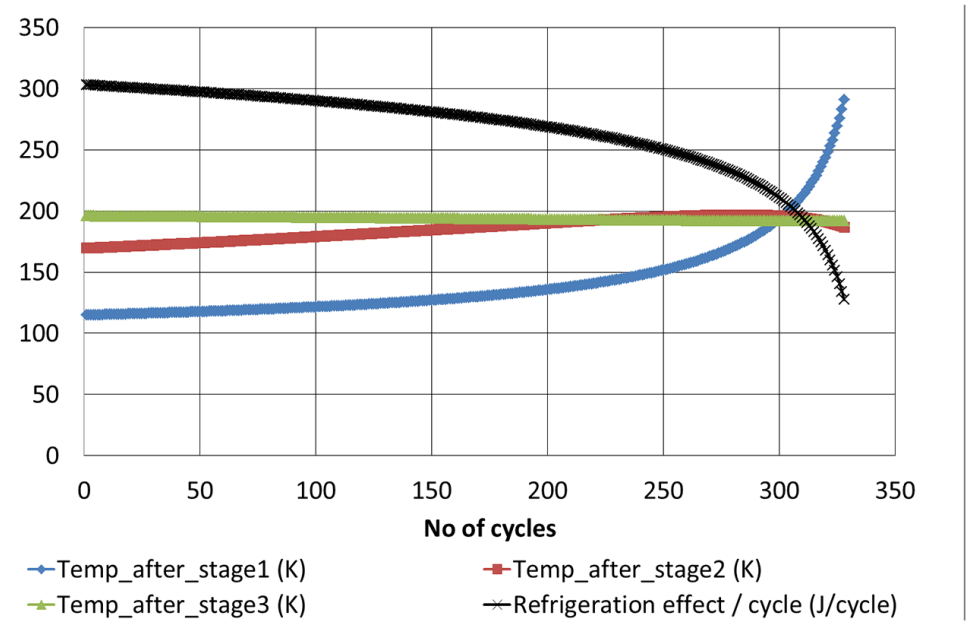

Figure 7 Air engine refrigeration characteristics - Fully pneumatic provision

consumption of the 1 liter of air was calculated. Assuming a constant vehicle speed of $50 \mathrm{kmph}$, the corresponding range of the vehicle was estimated. This range per liter was then used to get the volume of air required for a range of $150 \mathrm{kms}$. This value turned out to be 892 liters. The corresponding mass of the compressed air tank and total mass were then estimated as $580 \mathrm{~kg}$. 


\section{Midhun V.S et al.}

\subsection{Hybrid Operation}

In the second case i.e. hybrid operation, the fully charged batteries are exhausted first followed by the APE. The excess shaft work of the APE (the APE through the heat exchanges meets the complete refrigeration load) again fully charges the batteries and the electric mode resumes again as mentioned earlier. During electric operation the battery runs the motor to run the wheels and hence provides $7.06 \mathrm{~kW}$ constant power and also runs the compressor for a refrigeration of $9 \mathrm{~kW}$ with a system COP of 1.55 . It is to be noted that the APE operation in terms of work / cycle for each inlet air pressure is same as in the pneumatic operation because the air is expanded to ambient conditions always and the size of the engine is the same. The difference in the power output of the APE is brought about by changing the speed of the engine. The power consumption curves are shown in Figure 8, where the power requirements to run vehicle and additional power to batteries when the engine is run at a speed to provide the complete $9 \mathrm{~kW}$ refrigeration of using the heat exchanger are indicated.

Figure 8 shows the shaft power of the APE in the hybrid configuration. It also indicates the speeds of the APE in the two configurations. The normalized time is the ratio of the actual time elapsed during the operation

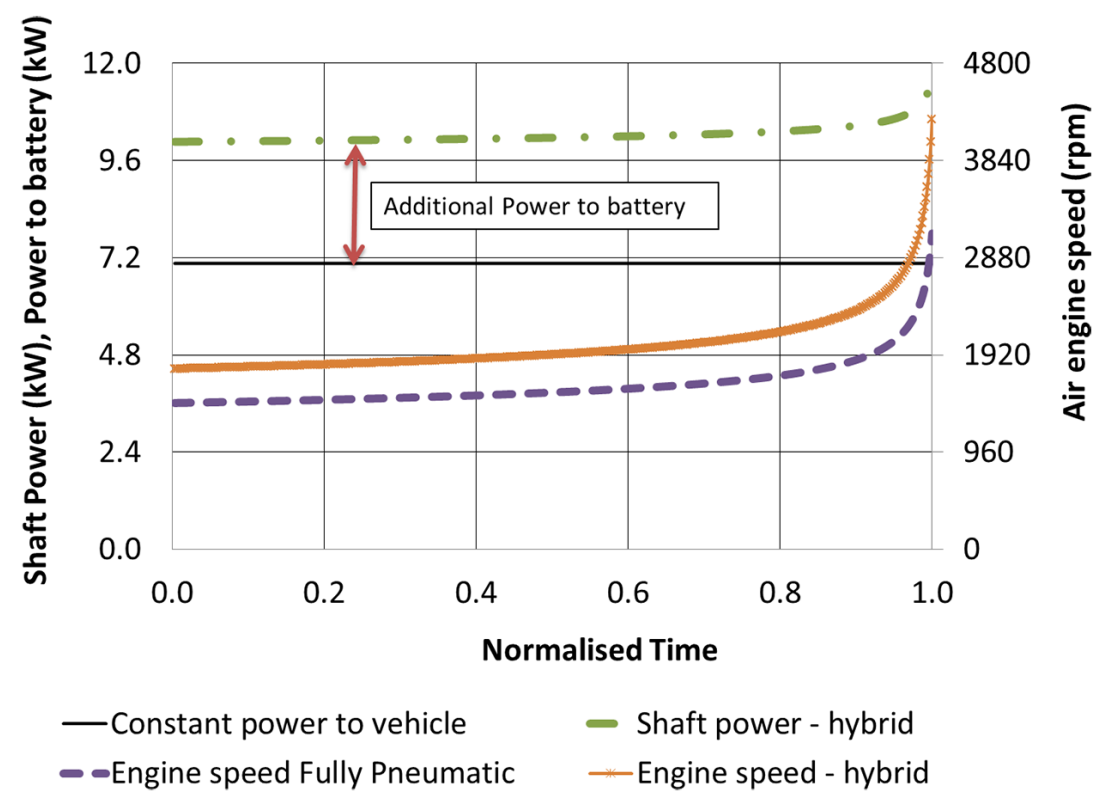

Figure 8 Power and speed curves during hybrid operation 
of the APE to the total time taken for the pressure in the compressed air tank to fall to the least operable value from 300 bar. Thus the actual time elapsed till the least operable pressure is reached will depend on the size of the compressed air tank and also on the rate of air consumption by the APE. The operation shaft power of the APE in the hybrid case rises sharply as the tank gets emptied. This is because the refrigeration effect as shown in Figure 7 drops significantly at these conditions which means that the mass flow rate through the engine has to increase. This results in higher shaft powers at these conditions. Since the air consumption rate of the APE is higher in the case of the hybrid configuration and the engine size is fixed, the speed in the hybrid configuration is also higher as seen in Figure 8. It may be noted that for the same normalized time, the time of operation of the APE is much higher in the case of the fully pneumatic version than the hybrid version.

\subsection{Comparison of Fully Pneumatic and Hybrid Configurations}

The total mass of the energy carrier is the sum of the masses of the batteries, compressed air and the compressed air tank in the case of the hybrid version. Figure 9 indicates the range obtainable with both the configurations for a given total mass of the energy carrier. It may be noted that the total mass if the vehicle is all the cases is fixed at $2500 \mathrm{~kg}$. We see that the hybrid operation is slightly

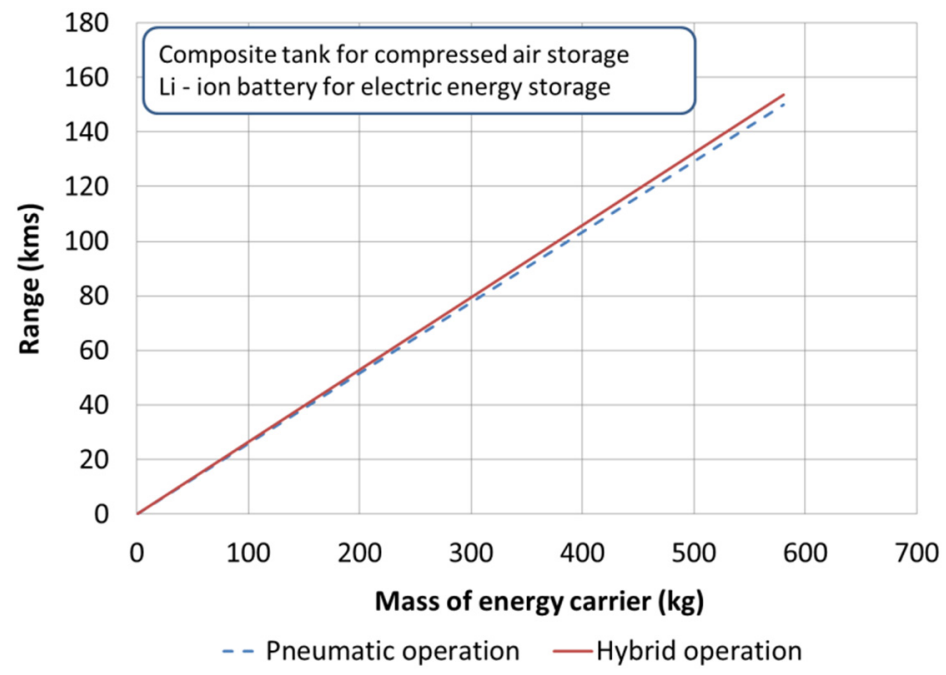

Figure 9 Mass of energy carrier and range - comparison between fully pneumatic and hybrid version 


\section{Midhun V.S et al.}

better. For a range of $150 \mathrm{~km}$ the mass of the energy carrier in the case of the fully pneumatic operation is $580 \mathrm{~kg}$. For the same mass of the energy carrier the hybrid version extends the range by $2.5 \%$. As the dependence on the battery for carrying energy increases this difference becomes more prominent. This is because the efficiency of energy conversion (charging and discharging) is better for the battery than the pneumatic version. On the other hand the battery can be charged and discharged only for a finite number of cycles as against the compressed air system that has a significantly higher life. Battery disposal also is another environmental problem. Considering these it may be said that the hybrid version provides longer life, with similar range to weight capability. It also leads to lesser environmental problems.

\section{Conclusion}

The conclusions based on the thermodynamic simulation done on two power train configurations namely fully pneumatic and pneumatic hybrid for propelling a light transport vehicle are given below:

- To produce the maximum cumulative work output from a given volume of compressed air tank at an initial pressure of 300 bar, the APE has to be designed for a supply pressure of 25 bar.

- The work per cycle of the air engine drops continuously with the inlet pressure of air. Hence, the speed of the APE has to be increased with time and this is more significant in the case of the hybrid version because the air consumption rates are higher.

- The ranges of the fully pneumatic configuration and the hybrid configuration are comparable for the same total mass of energy carrier.

- If environmental issues related to battery disposal and total life of the system are considered the fully pneumatic configuration offers potential benefits with comparable performance.

- Since the charging and discharging efficiencies of the batteries are better than the pneumatic case the overall efficiencies will be higher with the hybrid version.

On the whole the compressed air reciprocating engine with a continuously variable transmission is in itself a solution for zero emission transportation on applications requiring refrigeration on a light transport vehicle in the complete pneumatic mode and with improvements in efficiency possible in the hybrid operation mode. 


\section{NOMENCLATURE}

LTV - Light transport vehicle

APE - Air powered engine

$\mathrm{P}_{\text {in }}$ - Input supply of air pressure (bar)

$\mathrm{T}_{\mathrm{in}}$ - Input supply temperature of air $(\mathrm{K})$

$\mathrm{P}_{\mathrm{atm}}-$ Atmospheric Pressure (bar)

$\mathrm{N}-$ No. of stages

$\mathrm{P}_{\text {out }}-$ Output air pressure from engine (bar)

$\mathrm{n}$ - Polytropic index

$\mathrm{W}_{\text {stage }}-$ Work done at each stage $(\mathrm{J} /$ cycle $)$

$\mathrm{W}_{\text {shaft }}$ - Total work output from engine (J/cycle)

$\mathrm{N}_{\mathrm{rpm}}$ - Engine speed (rpm)

$\mathrm{C}_{\text {rate }}$ - Rate capacity $(\mathrm{J} / \mathrm{K})$

$\mathrm{H}_{\text {trans }}-$ Heat transfer work ( $\mathrm{J} /$ cycle)

$\mathrm{H}_{\text {refri }}-$ Heat transfer total (J/cycle)

$\varepsilon$ - Effectiveness

$\mathrm{T}_{\text {refri }}$ - Temperature of refrigerated space $(\mathrm{K})$

$\mathrm{T}_{\text {exp }}$ - Temperature after expansion $(\mathrm{K})$

COP - Co-efficient of performance

$\mathrm{W}_{\text {isothermal }}$ - Isothermal work output

$\mathrm{V}_{\text {batt }}$ - Volume of battery required (1)

$\mathrm{B}_{\text {en_den }}-$ Energy density of battery $(\mathrm{kW} \mathrm{h} \mathrm{/} \mathrm{l)}$

$\mathrm{W}_{\text {isothermal }}$ - Isothermal work output $(\mathrm{kJ})$

TDC - Top dead center

BDC - Bottom dead center

IVO - Inlet valve opening

IVC - Inlet valve closing

EVO - Exhaust valve opening

EVC - Exhaust valve closing

$\eta_{\text {eff }}$ - Isothermal Efficiency

$\mathrm{P}_{\text {refri }}$ - Refrigeration power $(\mathrm{kW})$

$\mathrm{m}_{\text {batt }}-$ Mass of battery required $(\mathrm{kg})$

$\mathrm{B}_{\text {sp_en }}-$ Specific Energy of battery $(\mathrm{kW} \mathrm{h} / \mathrm{kg}$ )

$\mathrm{p}_{1-4}$ - Pressure at each process point in stage

$\mathrm{v}_{1-4}$ - Volume at each process point in stage

$\mathrm{M}_{\text {air_tank }}$ - Mass of air in tank $(\mathrm{kg})$

$\mathrm{P}_{\text {tank }}$ - Initial Pressure of Air in Tank (bar)

$\mathrm{T}_{\text {tank }}$ - Ambient temperature $(\mathrm{K})$ 
$\mathrm{R}$ - Gas constant for air $(\mathrm{J} / \mathrm{kg} \mathrm{K})$

$\mathrm{H}_{\text {refri }}$ - Total refrigeration heat transferred $(\mathrm{kW})$

$\mathrm{P}_{1}$ - Constant power to vehicle $(\mathrm{kW})$

$\mathrm{P}_{2}-$ Constant refrigeration on vehicle $(\mathrm{kW})$

$\mathrm{W}_{\text {total }}$ - Total work to be done by electric drive

$\mathrm{T}_{\text {time }}-$ Run time (s)

$\mathrm{P}_{\text {shaft }}-$ Shaft power produced by APE $(\mathrm{kW})$

$\mathrm{W}_{\mathrm{n}-\text { stage }}-$ Multistage expansion work output $(\mathrm{kJ})$

CVT - Continuously variable transmission

\section{References}

[1] Havemann, H.A, Rao, N. N. N., (1956) Studies for a New Hot Air Engine, Indian Institute of Science, Bangalore, Vol. 37, No.3, July 1955; Vol.38, No.3, July 1956.

[2] Robertson, S.(1995) Air Car Design Manual, Pneumatic Options Design Library, 1995.

[3] Bossel, U.(2009) Thermodynamic Analysis of Compressed Air Vehicle Propulsion, European Fuel Cell Forum, February 2009.

[4] Carvalho, L.(2008) Exergetic Analysis of Compressed Air for Vehicular Propulsion, SAE 2008 - 36-0315.

[5] Creutzig, F., et al.(2009) Economic and Environmental evaluation of compressed-air cars, Environmental Research Letters, 4 (2009) 044011 (9pp) IOP Publishing.

[6] Schechter. M (1999) New Cycles for Automobile Engines, SAE paper 1999-01-0623, 1999.

[7] Trajkovic, S., et al. (2007) Introductory Study of Variable Valve Actuation for Pneumatic Hybridization, SAE 2007-01-0288, 2007.

[8] Automotive handbook (2011), 8th edition, published by Robert Bosch 2011, Postfacch 11 29, D-73201, Plochingen, 324-328.

[9] MoRTH/ CMVR / TAP-115/116 (Issue 4) - Chapter 39(2010), Central Motor Vehicles Rules, Ministry of Road Transport \& Highways, Government of India, March 2010

[10] Web reference - http://www.valeocompressors.com/en/tm-series, visited 10 September 2012

[11] Dossat, R. J.(2008) Priniciples of Refrigeration, Fourth Edition, Published by Dorling Kindersley (India) Pvt. Ltd., licensees of Pearson Education, 2008. 
[12] Doty, D., et al.(2009) Practical Application of a compact, high effectiveness, gas to gas, compound recuperator, with liquid intermediary(CRLI), Proceedings of the ASME 2009 Heat Transfer Summer Conference, HT2009-88372

[13] Nag P.K(2006) Engineering Thermodynamics, Tata McGraw-Hill Publishing Company Limited, 2006.

[14] Incropera, F.P, DeWitt, D.P (2007) Fundamentals of Heat and Mass Transfer, Wiley Publication, Fifth Edition, 2007.

[15] Baldwin, D.(2009) Design and Development of High Pressure Hydrogen Storage Tank for Storage and Gaseous Truck Delivery, FY 2009 Annual Progress Report DOE Hydrogen Program

[16] Larminie. J, Lowry. J (2003) Electric Vehicle Technology Explained, John Wiley \& Sons, Ltd, 2003.

\section{Biographies}

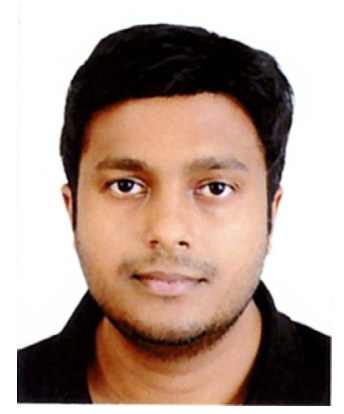

Midhun V S is a Senior Manager in Research and Development department of M/S Nissan Ashokleyland Technologies Limited, an automotive manufacturer. $\mathrm{He}$ is currently pursuing his M S (By Research) in Indian Institute of Technology, Madras under the guidance of Prof A Ramesh, in the Internal Combustion Laboratory.

He specializes in development of alternate fuel power train for commercial applications. He has been involved in dedicated CNG engine development for EURO IV and EURO V. He is specialized in CNG vehicle level layout design. He was part of team to develop world's first CNG PLUG IN HYBRID vehicle $\mathrm{He}$ has been part of design and testing of two and three gasoline engines. He was worked on calibration of air assisted direct injection on three wheeler application. He has presented 5 papers in International forums. Presently he is part of team specializing in the control system and combustion analysis. 


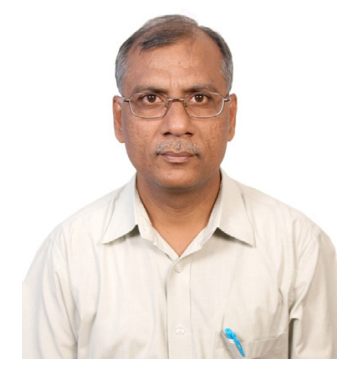

A. Ramesh is currently a Professor of Mechanical Engineering at the Indian Institute of Technology Madras (IIT Madras). He did his Ph.D in internal combustion engines in IIT Madras in 1990 and did his post doctoral research work in Ecole Des Mines De Nantes, France.

He has published over 125 research papers in International forums. His research interests include gasoline direct injection, homogeneous charge compression ignition, engine management, engine instrumentation, new and innovative engine designs and alternative fuels. He has guided several students for their doctoral and masters degrees. Several of his students have received best project awards during their masters program. His work has culminated in several innovative designs and components for engines. He has filed nine patents of which some are with automotive industries. Dr. Ramesh has been a member of government funded projects on alternative fuels, hydrogen energy, instrumentation, engine development and skill development.

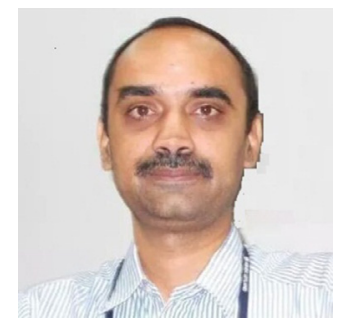

M Sathyanandan is Assistant General Manager (AGM) in the Research and Development division of M/S Nissan Ashokleyland Technologies Limited, an automotive manufacturer. He is head calibration and testing for the development of common rail direct injection (CRDI) engine platforms. He is in-charge for the control system development using MATLAB/SIMULINK for model based calibration. 
He has lead the team for Vehicle Management System working on MATLAB/SIMULINK algorithm validation, pseudo-code development, design documentation, calibration guidelines, algorithm development and testing of engine control systems. He has led the design and testing of 2 stroke single cylinder direct injected gasoline engine. He has also been part of team designed and proto developed a 4 stroke scooterette including a novel stepshift mechanism. He has also led team developing $1.5 \mathrm{~L}$ diesel common rail Naturally Aspirated and TCIC variants. 
